\title{
CanMEDS: time to teach the teachers
}

\author{
Andrew E. MacNeily, MD, FRCSC, FAAP
}

See related article on page 363

$\mathrm{H}$ ealth advocacy. What is it? How do we teach it? How do we evaluate it? How do we evaluate the teachers of it? These are questions that faculty and trainees struggle with.

In this issue of $C U A J$, Leveridge and colleagues ${ }^{1}$ have examined the perceptions of graduating Canadian urology residents regarding the most nebulous of the 7 CanMEDS core competencies. Like all perceptions, these ones are subject to potential bias that the authors acknowledge. Of concern is that $20 \%$ of urology residents were not aware that this competency existed, only $11 \%$ felt that it was frequently addressed by their attending staff in the clinical setting and nearly one-half did not have a mentor to emulate in health advocacy in urology. Of reassurance is that two-thirds of respondents felt that participation in health advocacy activities was an obligation of physicians and surgeons.

It would be interesting to survey the urological faculty at Canadian academic institutions to determine whether their perceptions mirror those of our trainees. For example, how many of us can define health advocacy and believe it to be an essential component of residency education? How many have participated in formal training in health advocacy? Verma and colleagues' work $^{2}$ represents a survey of faculty and residents from a cross section of specialties at Queen's University in 2002. (One urologist participated.) The findings were similar to the current study: none of the residents knew the health advocate role or its expectations of learners. Faculty and residents learned about health advocacy from role models, from an innate sense of values and from their parents. Although role modeling was felt to be invaluable, it was deemed insufficient. A graduated curriculum and sharing of resources across schools was required to optimize the acquisition of skills and knowledge about health advocacy in postgraduate training. Further, faculty development was sorely needed.

Although Royal College sponsored workshops on the CanMEDS competencies are beginning to emerge, there is still a lack of readily available tools and resources offered to educators. ${ }^{3}$ Until these resources are more accessible, it will continue to be difficult to champion health advocacy as anything other than "charity work." The same could be said of the communicator, collaborator and manager roles. The ACGME (Accreditation Council for Graduate Medical Education) outcomes project in the United States has established a toolbox of assessment methods for educators to teach and evaluate core competencies. Considerable effort has been put into faculty development in the form of online teaching modules. ${ }^{4}$ We should do the same.

Head, Division of Pediatric Urology, Department of Urological Sciences, University of British Columbia, Vancouver, BC

Competing interests: None declared.

\section{References}

1. Leveridge $M$, Beiko D, Wilson JWL, et al. Health advocacy training in urology: a Canadian survey on attitudes and experience in residency. CUAJ 2007;1: 363-9.

2. Verma S, Flynn L, Seguin R. Faculty's and residents' perceptions of teaching and evaluating the role of health advocate: a study at one Canadian university. Acad Med 2005;80:103-8.

3. Royal College of physicians and surgeons of Canada. Available: http://rcpsc.medical.org/canmeds/resources/index.php (accessed 2007 Sept 25).

4. Accreditation council for graduate medical education outcome project. Available: hittp://www.acgme.org/outcome/ (accessed 2007 Sept 24).

Correspondence: Dr. A.E. MacNeily, KO-134 BC Childrens Hospital, 4480 Oak St., Vancouver BC V6H 3V4; amacneily@cw.bc.ca 